\title{
DOSSIÊ - APRESENTAÇÃO
}

\section{LICENCIATURAS EM EDUCAÇÃO DO CAMPO E LETRAMENTOS MÚLTIPLOS: FORMAÇÃO DOCENTE E PESQUISA}

\author{
Mônica Castagna Molina ${ }^{1}$ \\ Rosineide Magalhães de Sousa ${ }^{2}$ \\ Organizadoras
}

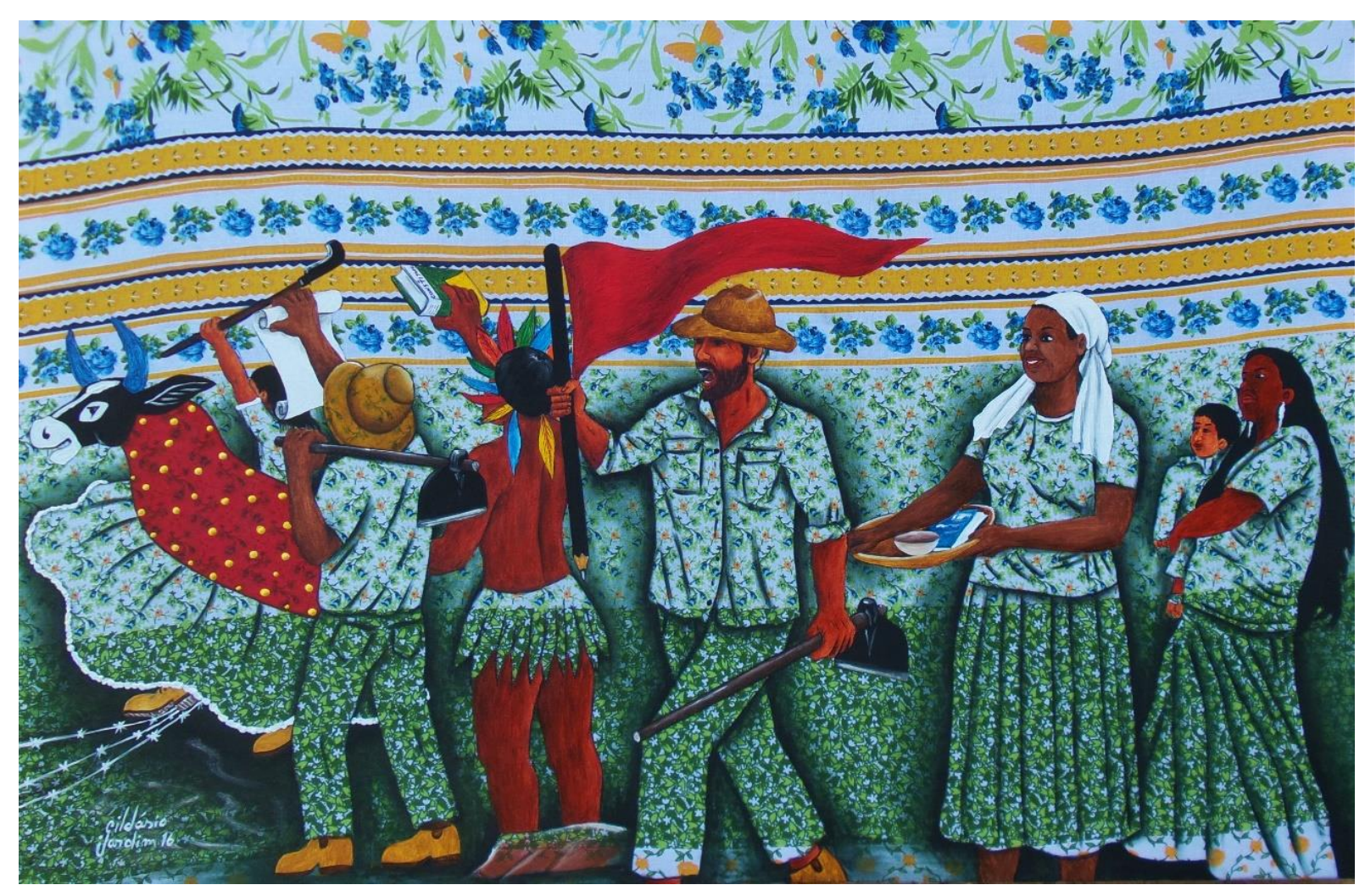

Imagem - Gildásio Jardim ${ }^{3}$

O Dossiê "Licenciaturas em Educação do Campo e Letramentos Múltiplos: Formação Docente e Pesquisa" apresenta resultados de pesquisas desenvolvidas sobre as Licenciaturas em Educação do Campo relacionadas aos Letramentos Múltiplos dos/as camponeses/as e educadores/as que atuam nas escolas do campo. Divulga, portanto, o conhecimento científico produzido pela Educação do Campo a partir dos Letramentos Múltiplos que ela proporciona, compreendendo que esses "resultam de atividades de leitura e de escrita de diferentes áreas do conhecimento e de contextos sociais do campo, com suas culturas e identidades" (SOUSA et al., 2016, p. 11).

A Licenciatura em Educação do Campo (LEdoC) foi concebida para garantir a formação, no âmbito da educação superior, de educadores/as que já atuam nas escolas do campo, bem

\footnotetext{
${ }^{1}$ Universidade de Brasília, Brasília, DF, Brasil.

${ }^{2}$ Universidade de Brasília, Brasília, DF, Brasil.

${ }^{3}$ Gildásio Jardim Barbosa tem 40 anos de idade e mora em Padre Paraíso, cidade do Vale do Jequitinhonha. Dedica-se à cultura popular, desenvolvendo trabalhos de pintura sobre tecidos estampados em tela. De seu trabalho, diz que "As estampas de tecido são lembranças das roupas das pessoas da minha comunidade que carrego em meu imaginário desde minha infância na zona rural." Para conhecer mais trabalhos do artista, acesse: https://gildasio-35.blogspot.com. Contato: gildasio-35@ hotmail.com.
} 
como para a juventude camponesa que nelas possa vir a atuar. Os cursos têm como contexto a escola de Educação Básica, com ênfase na construção da Organização Escolar e do Trabalho Pedagógico para os anos finais do Ensino Fundamental e do Ensino Médio. Essas licenciaturas objetivam promover a formação de educadores/as por áreas de conhecimento, habilitando-os/as para a docência multidisciplinar nas escolas do campo, organizando os componentes curriculares em quatro áreas do conhecimento: Artes, Literatura e Linguagens; Ciências da Natureza e Matemática; Ciências Humanas e Sociais e Ciências Agrárias.

Os cursos de Licenciatura em Educação do Campo objetivam preparar educadores/as para, além da docência, atuarem na gestão de processos educativos escolares e na gestão de processos educativos comunitários. Ao se pretender que as escolas do campo estejam aptas a contribuir para a formação de jovens capazes de compreender a complexidade do que ocorre no campo brasileiro na atualidade, é necessário formar educadores/as que atuarão nessas escolas e que sejam capazes de compreender criticamente esses processos e sobre eles intervir. É nesse sentido que se articulam intrinsecamente as três ênfases no perfil de educadores/as que se quer formar: atuação nas áreas de conhecimento, na gestão de processos educativos escolares e na gestão de processos educativos comunitários.

$\mathrm{Na}$ articulação desse perfil, reside significativa contribuição da LEdoC às políticas de formação docente, pois, como afirma Arroyo, há bases teóricas profundas inspiradas nas concepções da teoria pedagógica mais sólida, nos indissociáveis vínculos que os movimentos sociais do campo defendem entre "direito à educação, à cultura, à identidade e ao território. Dimensões esquecidas e que os movimentos sociais recuperam, enriquecendo, assim, a teoria pedagógica; abrindo novos horizontes às políticas de formação de educadores" (ARROYO, 2007,p. 163).

Associada à compreensão da intrínseca articulação entre educação, cultura, identidade e território do novo perfil de educador/a que as Licenciaturas objetivam formar, há outra importante especificidade no tocante aos métodos de formação docente por elas realizados: a estratégia de oferta da educação superior baseada na Pedagogia da Alternância. A organização curricular dessa graduação prevê etapas presenciais (equivalentes a semestres de cursos regulares) ofertadas em regime de Alternância entre Tempo Universidade e Tempo Comunidade, tendo em vista a articulação intrínseca entre a educação e a realidade específica das populações do campo (MOLINA, 2017).

Essa intrínseca vinculação do processo de formação desses sujeitos aos seus territórios, através da alternância pedagógica, tem resultado em um rico processo de letramentos desses/as educadores/as. A nossa concepção sobre Letramentos Múltiplos vem de Rojo (2009), de Kleiman e Assis (2016) e de Sousa et al. (2016) que consiste, resumidamente, em compreender a leitura de diferentes gêneros discursivos (BAKHTIN, 2003) que se configuram nas diferentes linguagens (oral, escrita, multimodal), em diversos estilos, na visão de leituras dos sujeitos da sociedade.

Aos Letramentos Múltiplos, adicionamos a visão de Street (2014) sobre os letramentos antropológicos e ideológicos, e de Freire (2008) sobre a leitura de mundo, visto que nas Licenciaturas em Educação do Campo, as leituras de mundo dos/as estudantes, em uma perspectiva (auto)etnográfica, se configuram por meio da cena de teatro, dos documentários (audiovisual), da mística, dos problemas de matemática, das aulas in situ de ciências naturais, da memória e história, do relatório de inserção na comunidade, do seminário integrador de estágio, do ensaio de literatura, isto é, de leituras que se ressignificam nas diferentes linguagens. A temática variedade linguística (BORTONI-RICARDO, 2011, 2004) está também inserida nos Letramentos Múltiplos, considerando a diversidade linguística dos/as estudantes da LEdoC e a interação entre a oralidade e a escrita e a leitura dessa interação.

Este Dossiê, portanto, reúne artigos que registram resultados de pesquisas na área de Letramentos Múltiplos nas Licenciaturas em Educação do Campo de todo o Brasil, e em 
contextos relacionadas a elas considerando as áreas de formação desses cursos: Linguagens (Linguística, Literatura, Teatro, Artes Visuais, Música); Ciências da Natureza e Matemática; Ciências Agrárias e Ciências Humanas e Sociais.

Esses cursos têm sido capazes de contribuir com a inserção dos sujeitos camponeses na Educação Superior em nosso país. E uma das características principais a se destacar é exatamente a contribuição das Licenciaturas em Educação do Campo, para que uma grande diversidade de sujeitos camponeses chegue às Universidades. Sob essa égide, no Seminário dos 20 anos da Educação do Campo e do PRONERA, realizado na Universidade de Brasília, em junho de 2018, ratificou-se a compreensão de que a Educação do Campo é agora Educação do Campo, das Águas, das Florestas, dos/das ribeirinhos/as, dos/as quilombolas, dos/as extrativistas, dos/as pescadores/as, das comunidades dos fundos de pasto, dos/as coletores/as de açaí, das quebradeiras de coco, dos/as gerazeiros/as, dos/as cerratenses etc. Isso evidencia a ampla diversidade de sujeitos coletivos que integram o Movimento da Educação do Campo em nosso país. Esse é um precioso patrimônio político-pedagógico construído e consolidado como patrimônio da classe trabalhadora, que conseguiu colocar em marcha a organização desses sujeitos coletivos em luta, pela garantia de seus territórios e do conhecimento, como instrumento de luta para neles permanecerem (MOLINA, 2020).

Atualmente, essas Licenciaturas estão já implementadas em todo o Brasil, nas suas cinco regiões, abrangendo 20 estados da federação. Em 2019, chegamos à marca de 47 cursos de Licenciaturas em Educação do Campo implementados, ofertados em 33 instituições de Ensino Superior no país, visto algumas instituições terem o curso em diferentes campi (MOLINA e MARTINS, 2019). Nas Licenciaturas em Educação do Campo estão matriculados mais de sete mil educandos/as, que representam uma rica diversidade de sujeitos e educadores/as do próprio campo que chegam às universidades, vindos/as de uma vasta variedade de biomas e culturas, compreendendo e sabendo das particularidades da produção material da vida em cada um desses territórios.

Essa rica diversidade de sujeitos camponeses presentes nas LEdoCs implica também no reconhecimento da diversidade territorial de onde eles/elas advêm e, consequentemente, das diferentes formas de produção material da vida; e das lutas que estes sujeitos coletivos protagonizam em cada um desses territórios. Essas pessoas trazem consigo preciosa bagagem cultural, associada às diferentes tradições que esses coletivos foram construindo e vivenciando nos processos de resistência em suas terras e territórios. Eles/elas contribuem muito com a própria Universidade para ampliar a compreensão dessas especificidades e formas de vida e relação com a natureza. Impactam, nos seus processos formativos vividos nas LEdoCs, as próprias escolas do campo onde atuam, que, na maioria das vezes, acabam tendo todos seus educadores e suas educadoras envolvidos/as em processos de formação conduzidos pelas universidades nos territórios camponeses, nas atividades de Tempo Comunidade.

No cenário das lutas pelos territórios, pelas culturas, pelas identidades, pelas histórias e memórias, e pela linguagem do campo, principalmente, pelo seu povo, não se poderia deixar de alçar, os letramentos ideológicos (STREET, 2014), que buscam leituras críticas, avaliativas, contraditórias, conflituosas, emancipatórias, transformadoras, libertadoras.

Portanto, os artigos que compõem o Dossiê "Licenciaturas em Educação do Campo e Letramentos Múltiplos: Formação Docente e Pesquisa" abordam diferentes questões sobre os desafios da formação de educadores/as do campo no âmbito das Artes; das Linguagens; das Ciências Naturais; da Matemática, entre outras áreas. Essas questões são abordadas nas diferentes teorias do conhecimento, porém todas vinculadas a perspectivas críticas, que refutam a neutralidade do conhecimento científico e que estão nas experiências de vida e na realidade dos contextos e dos sujeitos envolvidos. Dessa forma, deparamo-nos com trabalhos de discursos contra-hegemônicos, posicionamentos reflexivos de seus autores e de suas autoras, indicando 
o letramento ideológico (STREET, 2014). Isso revela o que é a formação de educadores na Educação de Campo, e como se alinha a esse tipo de letramento.

A organização do Dossiê dialoga com as dimensões formativas propostas pela Licenciatura em Educação do Campo: as áreas de conhecimento; a gestão de processos educativos escolares e a gestão de processos educativos comunitários. Dialoga também com os sujeitos coletivos que a demandaram, pondo um foco específico na atuação deles/delas nas escolas do campo.

Assim, o Dossiê está organizado em três blocos de trabalhos: o primeiro apresenta artigos que abordam diferentes frentes dos letramentos promovidos pelas Licenciaturas em Educação do Campo, em variadas dimensões da área de habitação de Artes; Literatura e Linguagens.

Resultantes de pesquisas de doutoramento sobre as Licenciaturas em Educação do Campo, os artigos apresentam preciosas reflexões sobre como o processo de aquisição e construção de Letramentos Múltiplos com os sujeitos camponeses, se promovido com intencionalidades emancipatórias pode contribuir significativamente com a ruptura de padrões hegemônicos impostos tanto à cidade quanto ao campo, pela indústria cultural. Os resultados encontrados novas práticas culturais nos territórios pesquisados, nas quais se recuperam saberes ancestrais das comunidades e se ressignificam experiências a partir de diálogos intergeracionais mediados por estes educadores em formação, e por sua apropriação crítica do uso de variados recursos audiovisuais.

Além das contribuições sobre a inter-relação entre o letramento ideológico e a concepção de interdisciplinaridade que sustenta as LEdoCs, partindo da materialidade da realidade, são apresentadas neste bloco questões que ampliam o debate teórico, trazendo novos elementos para a compreensão da Teoria das Representações Sociais em Movimento, a partir de reflexões das práticas artísticas de egressos das LEdoCs.

O segundo bloco traz artigos resultantes de pesquisas sobre as Licenciaturas em Educação do Campo, mas que tiveram como foco de produção de conhecimento os desafios enfrentados na formação de educadores/as que se habilitam na área de Ciências da Natureza e Matemática, tendo como pano de fundo as questões suscitadas pela complexa proposta da LEdoC da formação por áreas de conhecimento.

Os artigos apresentam relevantes resultados na formação de educadores/as capazes de promoverem a reelaboração dos planos de ensino buscando construí-los em diálogo com a realidade de seus educandos e suas educandas das escolas do campo, compreendendo a interdisciplinaridade como uma característica intrínseca da própria materialidade da vida humana, da realização do trabalho. Dialeticamente, apontam importantes críticas em relação à ainda persistente incapacidade de parte dos cursos compreenderem e se apropriarem da perspectiva de interdisciplinaridade proposta pelas LEdoCs, ao mesmo tempo que mostram, com os dados das pesquisas, a capacidade dos sujeitos camponeses de se apropriarem dos conhecimentos científicos na área das ciências, sem deixar de reconhecer e valorizar as memórias e saberes de sua ancestralidade, na relação com a natureza.

$\mathrm{O}$ terceiro bloco de artigos selecionados teve como foco pesquisas que buscaram compreender os resultados alcançados pelas LEdoCs nas ações materializadas por seus egressos e suas egressas, tanto nas escolas do campo quanto nas comunidades camponesas, diante do protagonismo de alguns dos sujeitos coletivos de direito que demandaram tais cursos: os/as assentados/as da Reforma Agrária; os/as quilombolas; os/as ribeirinhos/as. Portanto aqui, articulam-se reflexões tanto sobre a formação para gestão de processos educativos escolares quanto gestão de processos educativos comunitários, promovidas pelas LEdoCs.

São apresentados significativos resultados da ação dos/as egressos/as nas escolas do campo pesquisadas em diferentes regiões, mostrando o potencial da formação docente vivenciada nos cursos, revelando que a preocupação em garantir processos formativos que dialoguem diretamente com a realidade dos sujeitos camponeses se traduz em transformações nas práticas pedagógicas das 
escolas do campo, garantindo processos de ensino aprendizagem bem mais eficientes, como mostram os dados resultantes das pesquisas apresentadas neste bloco.

Importa destacar que há um relevante amálgama entre o conteúdo dos artigos que integram os três blocos: a concepção e a prática de formação que expressam os dados encontrados nas pesquisas que tais artigos sintetizam: uma formação docente na qual a pesquisa tem centralidade, uma formação que busca dotar os educadores que dela participam, de autonomia intelectual, forjando-os como sujeitos de práxis.

Em tempos de intensa disputa em torno das políticas públicas de formação docente, nos quais as forças privatistas e ultraliberais buscam redesenhar os marcos legais conquistados pela sociedade brasileira, os resultados das pesquisas apresentadas nos textos deste Dossiê erguemse como uma importante barreira de resistência. Mostram a importância e os resultados de uma política de formação docente, centrada na Epistemologia da Práxis, e os resultados significativos que produz. E, pela força de seus resultados, refutam a Epistemologia da Prática que tais forças tentam impor às políticas de formação docente na atualidade, através da Revogação da Resolução do CNE2\2015 e por sua substituição pela Resolução 2/2019, aprovada sem nenhum participação ou diálogo com a sociedade civil e com as principais organizações acadêmicas que estudam e pesquisam a formação docente no país: a ANFOPE; A ANPED; a ANPAE, entre outras (Silva, et al. 2020).

Além do Dossiê trazer artigos que abrangem as várias habilitações das Licenciaturas em Educação do Campo, buscamos trabalhos que expressam a diversidade territorial brasileira, tendo sido selecionadas pesquisas desenvolvidas nas LEdoCs, ou em sua perspectiva, das diferentes regiões do país, apresentando um panorama significativo das potencialidades e dos desafios enfrentados nos cursos. Nesse sentido, foi intencional a escolha de experiências já bastante consolidadas, buscando-se selecionar pesquisas que trouxeram casos de IES que oferecem a Licenciaturas em Educação do Campo há mais de uma década, e experiências mais recentes ainda em processo de estruturação, cujos desafios na produção do conhecimento relacionam-se tanto com o menor tempo de vivência na formação docente por áreas de conhecimento, quanto na menor experiência de alternância na Educação Superior.

Convidamos os leitores da Revista Linha Mestra a mergulharem neste vasto e diverso território, no qual são apresentados as enormes potencialidades e desafios que os Letramentos Múltiplos proporcionados pela Licenciaturas em Educação do Campo têm gerado, contribuindo para conhecermos mais o campo brasileiro e seguirmos juntos, através da ciência e da formação docente crítica, na construção de ações que fortaleçam a resistência ativa e que nos ajudem nos processo de acumulação de forças a para a construção de um país com igualdade e justiça social.

Uma excelente leitura a todos!

\section{Referências}

BAKHTIN. M. Estética da criação verbal. 4. ed. São Paulo, 2003.

BORTONI-RICARDO, S. M. Do campo para a cidade. São Paulo: Parábola, 2011.

BORTONI-RICARDO, S. M. Educação em língua materna. São Paulo: Parábola, 2004.

FREIRE, P. A importância do ato de ler. 49. ed. São Paulo: Cortez, 2008.

KLEIMAN, A. B.; SITO, L. Multiletramentos, interdições e marginalidades. In: KLEIMAN, A. B.; ASSIS, J. A. (Org.). Significados e ressignificações do letramento: desdobramento de uma perspectiva sociocultural da escrita. Campinas: Mercado de Letras, 2001. p. 169-198. 
MOLINA, M. C. Expansão das Licenciaturas em Educação do Campo: desafios e potencialidades. Educar em Revista, Curitiba, Brasil, n. 55, p. 145-166, jan./mar. 2015. Editora UFPR.

MOLINA, M. C. Contribuições das Licenciaturas em Educação do Campo para as políticas de formação de educadores. Educ. Soc., n. 38 (140), p. 587-609, 2017.

MOLINA, Mônica Castagna. Panorama das Licenciaturas em Educação do Campo nas IFES no Brasil. In: RUAS, José Jarbas; BRASIL, Anderson; SILVA, Cícero da (Org.). Educação do Campo: Diversidade cultural, socioterritorial, lutas e práticas. Campinas, SP: Pontes Editores, 2020.

ROJO, R. Letramentos Múltiplos: escola e inclusão social. São Paulo: Parábola, 2009.

SANTOS, C. M. dos; BIANCALANA, G. R. Autoetnografia: um caminho metodológico para a pesquisa em artes performativas. Revista ASPAS-PPGAC-USP, v. 7, n. 2, 2017.

SANTOS, M. S. dos. Memória coletiva e teoria social. 2. ed. São Paulo: Anna Blume, 2012

SILVA, H. S. A.; ANJOS, M. P.; MOLINA, M. C.; HAGE, S. A. M. Formação de professores do campo frente às "novas/velhas" políticas implementadas no Brasil: r-existência em debate. Dossiê: "Consequências do bolsonarismo sobre os direitos humanos, a educação superior e a produção científica no Brasil". Revista Eletrônica de Educação, São Carlos, UFSCAR, v. 14, p. 1-22, jan./dez. 2020.

SOUSA, R. M; MOLINA, M. C.; ARAUJO, A. C. Letramentos Múltiplos e interdisciplinaridade na Licenciatura em Educação do Campo. Brasília: DEX/UnB, 2016.

STREET, B. V. Letramentos sociais. São Paulo: Parábola, 2014.

STREET, B. V. Perspectivas interculturais sobre o letramento. Revista de Filologia Linguística Portuguesa da Universidade de São Paulo, n. 8, p. 465-488, 2007.

\section{Sobre as autoras}

Mônica Castagna Molina: Pós-doutorado em Educação pela UNICAMP. Professora Associada da UnB, atuando nos Programas de Pós-Graduação em Educação e Meio Ambiente e Desenvolvimento Rural, e na Licenciatura em Educação do Campo.

E-mail: mcastagnamolina@gmail.com.

Rosineide Magalhães de Sousa: Pós-doutorado em Linguística Aplicada pela UNICAMP. Professora Associada da UnB, atuando na Pós-Graduação em Linguística (Sociolinguística e Letramentos como Prática Social), área Linguagem e Sociedade, linha de pesquisa "Língua, interação sociocultural e letramentos" da Licenciatura em Educação do Campo, área de Linguagem. Líder do Grupo de Pesquisa (Socio)Linguística, Letramentos Múltiplos e Educação (SOLEDUC), certificado pelo CNPq.

E-mail: rosineide@unb.br. 